\title{
RETRATO DO INÍCIO DA CARREIRA DOCENTE
}

\author{
PORTRAIT OF THE BEGINNIG OF A TEACHER CAREER
}

\author{
RETRATO DEL INICIO DE LA CARRERA DOCENTE
}

\author{
Fabiana Alessandra Fonsaca Ruy ${ }^{1}$ \\ Laura Noemi CHaluh ${ }^{2}$ \\ ${ }^{1}$ Universidade Estadual Paulista "Júlio de Mesquita Filho" (UNESP), \\ Rio Claro/SP-Brasil \\ ${ }^{2}$ Universidade Estadual Paulista "Júlio de Mesquita Filho" (UNESP), \\ Rio Claro/SP-Brasil
}

RESUmo Este artigo é recorte de uma pesquisa que objetivou compreender as experiências vivenciadas pelos professores em início de carreira docente. Para isso, foi constituído um grupo do qual participaram professoras iniciantes. No grupo, com reuniões mensais, foram desenvolvidas propostas articuladas a discussões acerca do fazer docente. Algumas questões que nortearam este estudo foram: Quais são as relações que o docente em início de carreira estabelece na escola? Qual a importância destas relações e como marcam as ações cotidianas do professor na vida escolar? Como as experiências vividas afetam e constituem o "ser" professor? Como a escola recebe e acompanha os professores iniciantes no processo de inserção na escola? Tratou-se de uma pesquisa narrativa de experiências do vivido (LIMA; GERALDI; GERALDI, 2015) e a produção dos dados foi pautada no Paradigma Indiciário (GINZBURG, 1989). Neste artigo, damos visibilidade às experiências de uma das professoras iniciantes, a partir de uma de suas produções escritas, devido às especificidades e abrangência de suas vivências nessa fase da carreira, e estabelecemos relações com as abordagens da literatura sobre a temática. $\mathrm{O}$ trabalho sugere a necessidade de políticas de acolhimento a professores iniciantes.

Palavras-Chave: Professores Iniciantes; Formação de Professores; Pesquisa Narrativa.

Abstract This article is part of a research that aimed to understand the experiences lived by teachers in the beginning of their career. To achieve this, a group was formed with beginner teachers participating. In the group, with monthly meetings, we developed proposals articulated to the discussions related to teaching. Some questions that guided this study were the following: What are the relationships that the teacher starting a career establish in 
the school? What is the importance of these relationships and how they mark the teacher's daily actions in school life? How do the experience lived affect and constitute the teacher "being"? How does the school receive and follow these teachers in the process of insertion in school? This is a narrative research of lived experiences (LIMA; GERALDI; GERALDI, 2015) and the production of data was based on the Indicative Paradigm (GINZBURG, 1989). In this artic le, we g ive visibility to the experiences of one of the beginner teachers using one of her written productions, due to the specificities and extent of her experiences in this phase of her career, and we establish relationships with the literature approaches on this subject. This work suggests the need for policies for welcoming new teachers.

Keywords: Beginner Teachers; Teacher training; Narrative search.

RESUMEN Este artículo es un recorte de una investigación que tuvo como objetivo comprender las experiencias vivenciadas por los profesores en inicio de la carrera docente. Para eso, fue constituido un grupo del cual participaron profesoras iniciantes. En el grupo, con reuniones semanales, fueron realizadas propuestas articuladas a las discusiones acerca de la acción docente. Algunas cuestiones que nortearon este estudio fueron: ¿Cuáles son las relaciones que el docente en inicio de la carrera establece en la escuela? ¿Cuál es la importancia de estas relaciones u como ella macan las acciones cotidianas del profesor en la vida escolar? ¿Cómo las experiencias vividas afectan y constituyen el "ser" profesor? Cómo la escuela recibe y acompaña a los profesores iniciantes en el proceso de inserción en la escuela? Se trató de una investigación narrativa de experiencias e lo vivido (LIMA; GERALDI; GERALDI, 2015) y la producción de los datos fue pautada en el Paradigma Indiciario (GINZBURG, 1989). En este artículo, mostramos las experiencias de una de las profesoras iniciantes, a partir de una de sus producciones escritas debido a las especificidades y amplitud de sus vivencias en esa fase de la carrera, y establecemos relaciones con las abordajes de la literatura acerca da temática. El trabajo señaliza la necesidad de políticas de acogimiento a profesores iniciantes.

Palabras clave: Profesores Iniciantes; Formación de Profesores; Investigación NarraTIVA.

\section{INTRODUÇÃo}

Este artigo é um recorte de uma pesquisa de Ruy (2018), que teve como objetivo central compreender as experiências vivenciadas pelo professor em início de carreira docente, no contexto de um grupo de formação de professoras ${ }^{1}$ iniciantes da rede pública e particular de ensino, de um município do interior do Estado de São Paulo. As referidas professoras atuavam na educação infantil e ensino fundamental e tinham experiência de até três anos na carreira. A primeira autora deste trabalho foi formadora (e pesquisadora) do grupo. Das cinco docentes participantes, quatro tinham sido ex-alunas dela na graduação, em uma faculdade particular onde atuou como professora na formação inicial.

Utilizamos o termo "professora", pois no grupo havia apenas docentes do sexo feminino. 
Os contatos com as suas ex-alunas, anteriormente à constituição do grupo de formação aconteciam através do WhatsApp ${ }^{2}$, momento em que surgiam diálogos sobre a vida das professoras iniciantes na escola. É comum que após concluírem a formação inicial, na transição de estudantes a professoras iniciantes, estabeleçam vínculo com alguns professores e mantenham contato com diferentes propósitos, entre eles, falar das experiências do início da carreira docente.

Pela importância das problematizações socializadas por essas professoras em início de carreira, a primeira autora deste trabalho fez a escolha por instituir um espaço de diálogo onde pudessem circular as vozes dessas professoras iniciantes, que, em princípio, pareciam não ter o apoio da escola para poderem lidar com as incertezas e os desafios que todo início de carreira nos coloca. Passaram de um espaço não instituído de formação - a rede social WhatsApp, a um espaço instituído.

Assim, o grupo instituído passou a ser um espaço de formação legitimado e objeto de estudo da pesquisa da primeira autora deste trabalho. Algumas das questões que nortearam a pesquisa: 1) Quais são as relações que o docente em início de carreira estabelece na escola? 2) Qual a importância destas relações e como marcam as ações cotidianas do professor na vida escolar? 3) Como as experiências vividas afetam e constituem o ser professor? 4) Como a escola recebe e acompanha os professores iniciantes no processo de inserção na escola?

A perspectiva teórico-metodológica foi a pesquisa narrativa de experiências do vivido (LIMA; GERALDI; GERALDI, 2015); a formadora e pesquisadora considerou sua experiência significativa como formadora do grupo, e no entrelaçamento com as professoras iniciantes conseguiu deixar em evidência conflitos vividos nessa fase da carreira e instituir práticas formativas que potencializaram o diálogo e a reflexão no coletivo do grupo, deixando indícios da necessidade de pensar políticas de acompanhamento aos professores iniciantes. Segundo Lima, Geraldi e Geraldi (2015, p. 18), a necessidade de desenvolver pesquisas narrativas decorre pela "insatisfação com as produções no campo da educação que se caracterizaram por falar sobre a escola em vez de falar com ela e a partir dela; assim como falar do professor, ao invés de dizer dele; falar com ele".

$\mathrm{Na}$ metodologia de narrativa de experiências do vivido há peculiaridades relacionadas ao fato de que o sujeito da experiência a narra e, ao retomar as vivências e produzir a narrativa, extrai lições que configuram conhecimentos produzidos posteriormente, como resultado do embate entre a experiência e os estudos teóricos realizados após a narrativa das vivências. A pesquisa, posterior às experiências vividas, não antecede as experiências. A partir do vivido, temas e perguntas surgem e configuram ponto de partida para eleger os referenciais teóricos com os quais é possível dialogar; estes, suscitam as lições que se pode extrair das experiências vividas. Desta forma,

Como objeto empírico aqui é a experiência vivida, há muito de autobiografia, mas diferentemente desta não se faz emergir o sujeito, e sim a lição que se extrai da experiência, lição no sentido de conselho como apontava Benjamin

WhatsApp é um aplicativo de mensagens instantâneas e chamada de voz para smartfones. 
(1985). Por isso, em geral, elas apresentam também uma "novela de formação" (LARROSA, 1998) como referência para que se conheça o modo como o narrado marcou o narrador. Diferentemente de como ocorre na novela de formação de base autobiográfica, nesse grupo, o narrador, pesquisador e sujeito da pesquisa faz emergir uma história do trabalho da docência, da gestão ou outra que está pesquisando (GERALDI, C., 2000). Contrariamente à autobiografia, não é o todo do passado que aqui interessa, mas somente um (ou vários) acontecimento significativo, que se tornou "experiência" no sentido que lhe dá Larrosa (2004). Como refletem sobre o que ocorreu, essas pesquisas concorrem tanto para a formação profissional quanto para a constituição do pesquisador (LIMA, GERALDI; GERALDI, 2015, p. 27).

Segundo Lima, Geraldi e Geraldi (2015, p. 13) "O acontecimento é o que passou, enquanto o sentido da experiência se encontra naquilo que é narrável de um acontecimento, o que nos passou, nos co(moveu).

De acordo com Lima; Geraldi e Geraldi (2015), há consciência sobre a responsabilidade de pesquisar a própria prática, pois os sujeitos reconhecem que o processo de investigação do vivido é doloroso, pois a palavra habita uma arena de luta, um lugar de muitos embates de diferentes percepções sobre o trabalho, sobre a natureza, forma de viver, de dizer o mundo e de se dizer nele. "Trata-se de um eu aberto e inconcluso, susceptível aos discursos compartilhados" (LIMA; GERALDI; GERALDI, 2015, p. 15). Explicitam ainda, que pode haver uma falsa suposição de que não existe uma metodologia de investigação nas narrativas de experiências do vivido, devido ao fato de não haver um conjunto de passos previamente estabelecidos. Porém, ainda diante das dificuldades em enfrentar esse desafio, existe o olhar para a própria experiência como forma de produzir conhecimentos.

A produção dos dados no contexto do grupo de formação com as professoras iniciantes foi feita a partir de: gravações em áudio; diário de campo da formadora; diário de bordo do grupo; reflexões individuais e a fotografia, e foram analisados à luz do paradigma indiciário, o que implicou ir em busca de pistas, indícios e sinais que puderam revelar características peculiares apresentadas nas particularidades dos encontros, reunindo informações como peças de um enigma a ser decifrado (GINZBURG, 1989).

Em "Sinais - Raízes de um paradigma indiciário", Ginzburg (1989) apresenta o "método morelliano" de Giovanni Morelli, na área das Artes. Esse método consiste em não se atentar às características mais evidentes nas obras de Arte para a percepção de uma obra original ou uma réplica, mas a detalhes, a particularidades como: lóbulos da orelha, unhas, formas dos dedos das mãos e pés, que denotam a individualidade do artista. São características que passam despercebidas: evidências, pistas, que podem revelar algo, levar a desvendar um enigma. É dessa forma que Ruy (2018) reportou-se aos dados produzidos nos encontros formativos, para a análise, atentando-se às vozes, às escritas, às fotografias, na tentativa de ler nas entrelinhas; ouvir o que não foi dito; olhar para onde comumente não olhamos.

Ao todo foram realizados oito encontros, com reuniões mensais com o grupo, articulando propostas acerca do fazer docente, onde as professoras fizeram o exercício constante 
de analisar e refletir sobre a própria prática na escola, estabelecendo uma relação com o contexto e as relações que permeiam o dia a dia no cotidiano escolar; uma tarefa que permitiu que olhassem para si mesmas e para o outro, num processo alteritário (BAKHTIN, 2003) de constituição pessoal e profissional.

Neste trabalho, socializamos o retrato da constituição da professora Roberta, ${ }^{3}$ uma das produções escritas por ela, já que a mesma revela um olhar singular para a constituição do professor iniciante e para a carreira, através de sua atuação na rede pública municipal.

\title{
RETRATO DO PROFESSOR INICIANTE NA CARREIRA
}

O foco deste artigo é trazer as vivências de Roberta e que foram materializadas numa produção escrita que chamamos de retrato. A partir das vivências de Roberta e do que dizem do início da carreira, é possível rever as dimensões que constituem o choque de realidade vivida (HUBERMAN, 2007). As experiências socializadas pela professora iniciante apresentam relação direta com o retrato do início de carreira docente apresentado pela literatura sobre o assunto (GARCIA, 1999; MIZUKAMI, 2002; LIMA et al., 2006; HUBERMAN, 2007; NÓVOA, 2007).

As vivências da professora Roberta apresentam estreita relação com as experiências do universo dos professores iniciantes; retratam o que a literatura aborda a respeito desta fase da carreira docente; são o retrato micro (pessoal e profissional) de um retrato macro (do início na docência). As cenas que marcaram seu fazer docente e a constituíram uma iniciante, apontam para o que os estudos nesta área denotam como uma fase de momentos difíceis. Segundo Lima (2006),

\begin{abstract}
A respeito do início da docência, estudos vêm mostrando que esta é uma fase tão importante quanto difícil na constituição da carreira do professor. É um momento dotado de características próprias, no qual ocorrem as principais marcas da identidade e do estilo que vai caracterizar a profissional/professora ou o profissional/professor ao longo de sua carreira (LIMA, 2006, p. 9).
\end{abstract}

Alguns autores dedicados ao estudo sobre os professores iniciantes denominam ciclos de vida profissional, o que concerne às diferentes fases vividas no exercício da profissão. Visto desta forma, ao delimitar um período da vida profissional, e caracterizá-lo, o percurso realizado no campo de atuação é definido por fases. No caso dos docentes em início de carreira, há diferentes visões em relação ao tempo considerado como fase inicial da docência: Huberman (2007) considera inicial a docência até o terceiro ano, para Cavaco (1999), até o quarto ano na profissão, Veenman (1988) especifica como inicial até o quinto e Tardif (2007) defende que essa fase se estende até os sete anos. No processo formativo com as professoras iniciantes, do qual Roberta fez parte, considerei como fase inicial o período de três anos de exercício na profissão, fundamentada nos estudos de Huberman (2007).

3 A pesquisa foi aprovada pelo CEP - Comitê de Ética em Pesquisa, e o nome da professora é fictício. 
De acordo com Huberman (2007), as fases vividas pelo professor variam de acordo com as vivências de cada um, não especificamente na mesma ordem em que são categorizadas, e, desta forma, não ocorrem sempre ao mesmo tempo. O início da carreira docente é marcado por conflitos, e, de acordo com o autor, passa por fases denominadas ciclo de vida profissional do professor. O estágio de sobrevivência é o primeiro deles, cujo professor entra em choque com a realidade existente no campo de atuação e o vivido na formação inicial. Acontece quando há o confronto inicial com a situação profissional, um distanciamento entre os ideais e a realidade cotidiana. $\mathrm{O}$ de descoberta está relacionado às expectativas, desejo de conhecer e experimentar; experimenta-se a sensação de fazer parte de um determinado campo profissional, é o olhar para o momento inicial de carreira e enxergar-se como profissional, desejando sentir-se pertencente ao grupo, estágio este que, muitas vezes permite que o professor sobreviva aos desafios do primeiro. Huberman (2007, p. 39) aponta que "com muita frequência, a literatura empírica indica que os dois aspectos, o da sobrevivência e o da descoberta, são vividos em paralelo, e é o segundo aspecto que permite aguentar o primeiro". O início de carreira apresenta-se como um processo singular na constituição do docente, através dos saberes apreendidos ao longo do exercício da profissão nesta fase.

Roberta retrata sua experiência sobre o início da carreira na escola e enuncia outras vozes, que soam uníssonas, o que permite formar uma imagem mental, onde enxergamos um retrato que revela de que forma são constituídas as relações estabelecidas nesse universo, ${ }^{4}$ e como se constitui o profissional docente.

Apresentamos aqui um fragmento de seus relatos, sobre o que vivenciou na primeira escola onde iniciou seu fazer docente:

Dois dias antes do início das aulas, mais precisamente no início de fevereiro
de 2015, as professoras se reuniram, para realizarem o planejamento e parti-
ciparem da reunião com a coordenação e direção. Quando cheguei à escola,
a vice-diretora estava na secretaria, e pediu que eu seguisse a professora de
Educação Especial, que havia acabado de chegar à escola e se dirigia à sala
onde seria a reunião, pois ela (vice-diretora), não poderia sair da secretaria
naquele momento. Eu não conhecia a escola, por isso fiz o que ela me pediu.
Chegando ao local da reunião, fiquei espantada. Ninguém conversou comigo,
me senti um peixe fora d'água. Nenhuma professora perguntou meu nome, nem
quem eu era, nem em que sala eu trabalharia naquele ano. A coordenadora
iniciou a reunião dando as explicações gerais de como seria o trabalho (pro-
jetos, currículos entre outros assuntos). (Fragmento do Relatório da professora
Roberta sobre sua trajetória no início da carreira - Março/2016.)

Quando o professor iniciante chega à escola, o fato de não conhecer a instituição faz com que se sinta deslocado, e o que deseja é ser acolhido. Roberta não teve a oportunidade

4 Não desejamos generalizar ou apontar apenas o lado negativo, com a ideia de "formar uma imagem mental" enxergando o retrato das relações que se estabelecem nas escolas. Há trabalhos positivos em muitas unidades escolares.

138 Comunicações | Piracicaba | v. $26 \mid$ n. $23 \mid$ p. 133-149| set.-dez. 2019 
do acolhimento, e seu relato explicita este fato, ao dizer que ninguém conversou com ela ou quis saber quem era e o trabalho que realizaria. Isso sugere que nem todas as escolas e/ou equipes estão preparadas para receber os professores novatos e desenvolver ações capazes de situá-los quanto ao trabalho desenvolvido. Acreditamos que é função da escola oferecer esse acolhimento. Cabe à equipe gestora envolver os professores que chegam, a fim de que compreendam sobre a concepção de educação daquele novo contexto, para que possam contribuir com os projetos e sintam-se parte da equipe.

Segundo Garcia (2010, p. 15-16), "Os mestres e professores, geralmente, enfrentam sozinhos a tarefa de ensinar. Somente os alunos são testemunhas da atuação profissional dos docentes". Para o autor, a docência é uma das poucas profissões caracterizadas por uma maior solidão e isolamento.

A seguir, apresentamos outro fragmento do retrato de Roberta e que diz mais uma vez dos sentimentos gerados por uma equipe que não acolhe, por estar com um grupo de professoras que, a princípio, pareciam não se articular para trabalharem juntas.

Fica visível no relato a seguir que as dificuldades encontradas se referiam ao momento vivido, na falta de apoio da equipe:

[...] No horário que foi destinado ao planejamento anual, não houve o planejamento anual. As professoras conversavam sobre assuntos que nada tinham a ver com a escola. Eu esperava um planejamento de trabalho, em que poderíamos trocar pensamentos, projetos de trabalho entre outras coisas, mesmo para que eu pudesse aprender na prática a dinâmica de sala de aula. A outra professora eventual também era iniciante, e esperava o mesmo que eu. No dia seguinte que seria mais um dia de planejamento, houve a reunião com a diretora. Primeiramente, ela pediu que todas se apresentassem, alegando que havia professoras novas. Em seguida iniciou a reunião e percebi que nenhuma professora falava nada, não questionavam nada, pareciam com receio, ou seja, era um silêncio absoluto.

$[\ldots]$

Como já estava cansada daquilo tudo, com uma decepção sem fim, perguntei à coordenadora a respeito do planejamento e ela me respondeu que ninguém fazia planejamento coletivo, e que ali as professoras já trabalhavam há bastante tempo e já sabiam o que trabalhar. (Fragmento do Relatório da professora Roberta sobre sua trajetória no início da carreira - Março/2016.)

Um encontro que explicitamente deveria promover a organização do trabalho pedagógico na escola, mas que pelas considerações de Roberta se apresenta como um espaço onde o que circula é o silêncio, é a concepção de que as professoras experientes por terem tempo de exercício na docência, não precisam aprender, porque já sabem tudo, o que mostra uma concepção de formação e de sujeitos acabados, como se existisse um tempo no qual acabaríamos o processo de formação e por isso estaríamos prontos, não seria necessário aprender e nos rever enquanto professores.

Das considerações acima relatadas, fica explícita a concepção de formação sustentada pela coordenadora, uma vez que ao dizer que os professores que trabalhavam lá há bastante 
tempo já sabiam o que fazer e por isso não precisavam rever seus planejamentos. Isto diz de uma ideia de "sujeito acabado". Contra essa concepção acreditamos que somos sujeitos/professores inacabados (FREIRE, 2008) se pensarmos que somos sujeitos históricos e sociais e convivemos com diferentes grupos sociais com os quais aprendemos/ensinamos, constituindo-nos outros, num processo alteritário (BAKHTIN, 2003) onde vamos nos (re) constituindo, considerando que o aprendizado acontece nas relações dialógicas.

Trazemos as considerações de Zeichner (2002, p. 28), quem critica "que a abordagem dominante, tem sido preparar os professores para serem implementadores eficientes das políticas desenvolvidas por quem está fora da realidade da sala de aula". A partir das considerações do autor, acreditamos que isto seria um fator que pode levar o professor a ser um agente passivo, e "que sejam servidores públicos não reflexivos e obedientes, que fielmente implementem um currículo prescrito pelos governos usando métodos de ensino prescritos" (ZEICHNER, 2002, p. 28).

Retomando a situação das professoras veteranas, na escola onde Roberta dá início à sua carreira, é possível indiciar esse modelo de professores (que seguem as prescrições de um currículo predeterminado, sem reflexão sobre o contexto em que atuam, desconsiderando a realidade dos alunos em sala de aula). Nesta perspectiva, a escola perde vida, deixa de ser espaço democrático, lugar onde se produz conhecimento, em detrimento de um espaço onde este chega pronto e é aplicado.

A leitura que fazemos da vivência de Roberta na primeira escola aponta evidências de que isso foi um problema para a professora em sua passagem pela escola, quando queria compreender o movimento daquele contexto. Desejava estabelecer trocas (refletir a partir delas), encontrar seu lugar na equipe, interagir com o grupo, expressar-se (dialogar); viver a fase da descoberta, movida pelo entusiasmo do início da carreira.

Segundo Fontana (2000, p. 109), “[...] a professora não está pronta em nós quando começamos a trabalhar. [...] não está pronta nunca, por mais estáveis, duráveis e semelhantes que pareçam ser nossas características como profissionais". Olhamos para a vivência de Roberta e nos parece evidente: de um lado a professora iniciante, que ainda não se sentia preparada netse início de carreira, e, do outro, as professoras veteranas, que davam conta de seus planejamentos, sozinhas, pois já dominavam os aspectos necessários para esta tarefa. E a relação entre estas professoras (iniciantes e veteranas)? Questionamos: qual era o mecanismo de formação utilizado pela equipe gestora para a formação na escola? É possível inferir que nesta unidade escolar não havia uma prática de acolhimento aos iniciantes?

Concordamos com Cunha (2011 apud ROMANOWSKI; MARTINS, 2013, p. 4), quando explicita que:

A compreensão de que este professor está numa fase de transição, iniciando suas primeiras experiências concretas, colocando em prática suas primeiras aulas, buscando aplicar os conhecimentos adquiridos durante sua formação, nem sempre é observada, pois se desenvolve uma representação de que sua formação foi suficiente e lhe propiciou preparo necessário para o exercício da docência (CUNHA, 2011 apud ROMANOWSKI; MARTINS, 2013, p. 4). 
Roberta buscou compreender o universo da escola à qual chegou, na tentativa de mobilizar seus conhecimentos carregados na bagagem (da formação ao longo da vida até a formação inicial); porém, ao buscar sua estabilidade e mobilizar os instintos de sobrevivência (desejando fazer diferente, o melhor, e transformar) não encontrou o apoio necessário para entender o contexto escolar, que seria o passo seguinte, visto que a equipe gestora e os professores veteranos tinham como tarefa acolher a professora. Nesse momento, só a formação inicial não daria conta, pois as informações e aprendizados que a professora precisava naquele momento ainda não estavam em sua bagagem, e faziam parte do cotidiano daquele contexto em específico.

Para além das dificuldades encontradas para fazer parte do grupo de professores e ser acolhida, Roberta também explicita outro tipo de dificuldades que enfrentou: como lidar com os alunos e qual o apoio que encontramos para promover a aprendizagem das crianças?

O meu aluno cada dia mais dando trabalho na escola, então a coordenadora resolveu chamar a mãe. Fui fora do meu horário de trabalho, conversamos com a mãe e essa relatou que ela já havia sido usuária de drogas e que ficou internada, que agora estava bem, mas que tinha muito medo que o filho, futuramente, também se envolvesse com drogas, e a diretora respondeu a ela que tomasse cuidado, porque geralmente os pais pagam na mesma moeda. Eu fiquei horrorizada com tanta insensibilidade e falta de carinho das professoras e direção frente aos alunos. Percebia que não se preocupavam com os alunos. Esse dia pra mim foi o fim do fim. Conversei com meu marido, e resolvi sair dessa escola. (Fragmento do Relatório da professora Roberta sobre sua trajetória no início da carreira - Março /2016).

Na fala de Roberta, a busca por apoio para lidar com as dificuldades de seu aluno que apresentava comportamentos pouco assertivos foi atendida, porém, ainda que tenha recebido um suporte da diretora, a abordagem utilizada para a conversa com a mãe de seu aluno não foi assertiva, e a professora que já estava sentindo-se à margem da equipe, com dificuldades em ajustar-se à rotina da escola, decide deixar a instituição. É perceptível que a falta de acolhimento causa transtornos ao professor iniciante nessa fase da carreira e que, em alguns casos, nem mesmo o desejo pelo fazer diferente permite aguentar. A falta de sensibilidade da diretora denota que não havia um olhar e ações centradas na criança, focados para o desenvolvimento da aprendizagem, de forma a criar estratégias que permitissem acolher às especificidades do aluno.

De acordo com Martins, Souza e Oliveira (2017, p. 7), “A falta de apoio e de acompanhamento favorece o sentimento de descrença em relação à docência e, até mesmo, o abandono da profissão". Cabe ressaltar, que de todas as histórias em início de carreira, no grupo de formação de professoras iniciantes, Roberta foi a única que não permaneceu na escola onde iniciou seu fazer docente, diante dos conflitos que se apresentaram; desistiu de uma turma de alunos do Ensino Fundamental.

Estas questões eram compartilhadas no grupo de formação junto com as outras participantes que também eram iniciantes. O diálogo possibilitava desvelar de que forma esses 
acontecimentos eram naturalizados em todas as escolas. Roberta não foi acolhida pela equipe, e, como professora iniciante, chegando a um lugar desconhecido e não compreendendo o movimento da escola, tampouco dominando o fazer docente (que vai constituindo-se ao longo da carreira e de acordo com o contexto de atuação, assim como nas relações que estabelece com o grupo de trabalho, com os alunos e famílias), sentiu-se perdida, tolhida, assustada e sozinha. Este foi o motivo pelo qual procurou apoio fora da escola, com amigas da turma da graduação e com ex-professoras.

Marcelo Garcia (1999 apud CUNHA, 2015, p. 86) vê a formação "como um processo de desenvolvimento de estruturação da pessoa que se realiza com um duplo efeito de uma maturação interna e de possibilidades de aprendizagem, de experiências dos sujeitos". Segundo Cunha (2015) a formação tem relação estreita com o lugar e o tempo em que se realiza, tendo esses lugares como múltiplos do ponto de vista de que é um processo vital que nos acompanha enquanto vivemos, assim como o tempo dedicado para tal. Os autores nos provocam a pensar que Roberta não foi acolhida ao iniciar como professora na carreira e na primeira escola, lugar este que dá indicativos de que não havia um olhar voltado à formação contínua. É possível compreender as dificuldades enfrentadas pela professora neste retrato, como um estágio de sobrevivência (HUBERMAN, 2007), onde mobilizou os conhecimentos da bagagem que carregava consigo da formação inicial; buscou apoio de seus pares e da coordenação; solicitou apoio fora da escola; atendeu à mãe do aluno que apresentava comportamento pouco assertivo e dificuldades de aprendizagem (atribuições relativas à sua função como professora) e suas ações não foram suficientes para o seu fazer docente naquela escola, o que aponta para indícios de que, por mais que a professora colocasse em prática seus conhecimentos adquiridos ao longo da formação inicial, o que acontecia na realidade da escola onde era iniciante, parecia não subsidiar suas ações. Por mais que se visse como profissional, e ativasse todos os dispositivos para sua ação, naquela instituição não deu conta sozinha. Não conseguiu avançar, não houve fortalecimento dos vínculos com o grupo de profissionais.

\section{Professora iniciante na Rede e na ESCOla}

Neste estudo, como já referido anteriormente, consideramos como iniciantes as professoras com até três anos de experiência (HUBERMAN, 2007), porém, acreditamos que independentemente do tempo de exercício na carreira, outros fatores influenciam para que o professor possa sentir-se um iniciante, dentre eles, a transição de uma escola para outra, que exige do professor um tempo para a adaptação ao novo contexto, para conhecer a equipe de trabalho, a organização do trabalho pedagógico, os alunos, famílias, dentre outras questões diretamente relacionadas à sua atuação.

Ao tratar sobre o universo dos professores iniciantes, Príncepe (2017) caracteriza a fase de início na carreira docente considerando como iniciantes até o terceiro ano em exercício, ou mais (na rede de ensino), como um dos momentos de desenvolvimento profissional que carrega consigo experiências acumuladas: enquanto alunos (pensando em todas as 
etapas de ensino da educação básica), a formação inicial (graduação) e a continuada (que pode acontecer na escola, redes de ensino, por iniciativa do professor, em espaços não formais). Estes são atributos que compõem o processo de desenvolvimento profissional docente, o que aponta para o fato de que, além da teoria, a prática subsidiada pela formação na escola e/ou na rede de ensino, são fatores impulsionadores e importantes para a constituição do professor iniciante. Outro fator, segundo a autora, é que o desenvolvimento profissional como iniciante pode ocorrer, ainda que o professor já tenha iniciado na rede, ao mudar de escola.

Roberta também viveu outro momento ao iniciar na segunda escola; buscou a princípio conhecer a equipe, saber sobre os alunos e como o trabalho era desenvolvido. Tudo era novo e diferente, ainda que atuasse na mesma rede de ensino. Foi até a escola com lágrimas nos olhos e muita insegurança, pois iniciaria em outra unidade escolar onde precisaria de apoio para conhecer os projetos de trabalho, o PPP (Projeto Político Pedagógico), a equipe gestora, os alunos, dentre outras questões que cada escola apresenta como especificidade devido à realidade local. A professora desejava ser acolhida, ainda que a primeira experiência não tenha sido como desejou. Quando um professor chega a uma escola, é o que se considera como algo normal a acontecer (ser acolhido). Desta forma, além de uma iniciante na rede, Roberta era novamente uma iniciante na escola, neste novo contexto em que atuaria. A fala da professora sobre seu sentimento ao ir até a escola para conhecer, revela a insegurança, causada pela primeira experiência, mas também o alívio em viver uma nova história em sua trajetória, que estava apenas iniciando:

Fui então conhecer a escola, conversar com a diretora e coordenadora. Senti-
-me acolhida pelo secretário da escola. Disse-me: "seja muito bem-vinda", e
me levou até a direção. Confesso, eu estava com lágrimas nos olhos de medo,
de emoção, não sei dizer. A diretora, com sorriso no rosto, me explicou so-
bre a classe, que era uma sala dificil, mas que estavam ali para me ajudar.
Apresentou-me à coordenadora, que também me acolheu, dizendo que poderia
contar com ela para tudo, que estava ali para me ajudar. E de fato foi assim.
Ajudou-me em tudo, até nas aplicações de provas da Secretaria da Educação,
que estavam atrasadas. Posso dizer que se tornaram minhas amigas: direto-
ra, professoras, coordenadora, enfim, todos. Posso dizer que a Creche foi um
presente. Trabalhar lá foi uma alegria, uma realização. Os alunos, realmente,
difíceis na questão de disciplina, mas todos trabalharam em equipe. (Fragmen-
to do Relatório da professora Roberta sobre sua trajetória no início da carreira
- Março/2016).

Neste relato Roberta revela a importância do acolhimento ao chegar em uma nova escola, o que contrapõe sua vivência ao iniciar, quando sentiu-se "um peixe fora d'água". Denota que, mesmo vivenciando problemas relacionados ao comportamento dos alunos, tinha uma equipe que trabalhava unida, e essa questão fez a diferença para o desenvolvimento de seu trabalho quando sentiu que poderia vivenciar uma dinâmica coletiva nas ações cotidianas naquele contexto. A dimensão do trabalho coletivo implica que todos os atores 
estejam envolvidos no processo, utilizando de ferramentas e dispositivos que permitam refletir sobre os rumos apontados no PPP- Projeto Político Pedagógico.

Consideramos a concepção de trabalho coletivo a partir de Chaluh (2008). Segundo a referida autora, as dimensões do trabalho coletivo podem ser pensadas a partir das seguintes questões: "a contradição e/ou o conflito, a conscientização, a enunciação da resposta e a concretização na ação da enunciação" (CHALUH, 2008, p. 190). O que implica que o grupo explicita os problemas, toma consciência deles, define propostas de ações, para posteriormente efetivar suas ações na concretude da vida.

Para Cunha (2014), a possibilidade de as aprendizagens ocorrerem se dá quando existe uma cultura institucional que as estimulam, valorizam. Enfatiza que as instituições devem ser vistas como principais dispositivos de formação dos professores, confiando e compreendendo o professor como um intelectual, um adulto que aprende ao refletir sobre o que faz.

Para Pinto (2016), retomar o PPP anualmente, nos primeiros espaços de formação na escola, permite rever a proposta do trabalho pedagógico para as professoras que são novatas, e suscitar novas discussões. Segundo a autora, no exercício de sua função como formadora, privilegia este momento por acreditar que este espaço orienta o trabalho que será realizado na escola durante o ano, e oportuniza a construção do planejamento.

Na Conferência "Desenvolvimento profissional de professores para a qualidade e para a equidade da aprendizagem ao longo da vida", em Lisboa, Nóvoa (2007) explicita que é preciso passar a formação de professores para dentro da profissão. Enfatiza que esta constatação se refere à necessidade de os professores ocuparem um lugar de predominância na formação de seus pares. Para o autor, as mudanças serão significativas neste campo, se a comunidade dos formadores de professores e a comunidade dos professores estabelecerem uma relação entrelaçada.

Príncepe (2017, p. 18) considera que sentir-se "pertencida a um corpo profissional" é ter "[...] reacendida a chama de continuar a ser professora". A referida autora, no início de sua carreira docente, passou por momentos difíceis, assim como Roberta e muitas outras professoras iniciantes na escola, lugar onde iniciam seu fazer docente; e, na segunda experiência, teve a oportunidade de descobrir a possibilidade em continuar na carreira, assim como Roberta.

Consideramos que é nas relações dialógicas que construímos e nos constituímos, num movimento também de constituição dos outros tantos que comigo interagem; no encontro com o outro, "pressupondo-se o Outro como existente e reconhecido pelo 'eu' como Outro que não-eu, e a dialogia, pela qual se qualifica a relação essencial entre o eu e o Outro" (GERALDI, 2003, p. 42). Compreendemos que em um grupo de pessoas onde há a presença forte e marcante da linguagem, do diálogo, onde todos se sentem autorizados a falar e ouvir é possível contrapalavrar (MIOTELLO, 2012), entrar em consenso, refletir, transformar (neste caso, num processo em que as reflexões giram em torno de um objetivo comum, de acordo com a proposta e concepção de educação da escola, expressa no PPP, documento que legitima as ações desenvolvidas, constituído coletivamente). Consideramos, assim, que 
o exercício do diálogo tem que ser o fundamento de todo processo que esteja atento à formação dos professores.

\section{RETRATO DAS LIÇÕES APREENDIDAS...}

Ao compartilhar suas experiências após o ingresso na carreira docente, Roberta assumiu uma postura enquanto sujeito em constituição, retratada por inúmeras dificuldades como parte do processo de constituir-se profissionalmente através das relações que se estabelecem na escola.

Roberta enfrentou problemas que demandavam o apoio da equipe gestora para que pudesse adaptar-se ao movimento do contexto vivido, sendo capaz de gerir todas as atribuições que lhe cabiam (que eram novas e desafiadoras). A formação continuada no espaço escolar era necessária para que a professora conseguisse desenvolver seu trabalho e sentir-se pertencente àquela equipe de trabalho. $\mathrm{O}$ acolhimento, tão importante nessa fase da docência, demonstra ter sido negado, e a professora desistiu de sua turma de alunos.

Encontramos em Zeichner (2002, p. 28) suporte para compreender esse processo vivido por muitos professores iniciantes ao chegarem à escola e se sentirem deslocados e sozinhos, quando o autor enfatiza que "os investimentos realizados na educação possuem uma clara tendência de investir em livros didáticos e tecnologia educacional, ao invés de investir em pessoas". Segundo o autor não há interesse no desenvolvimento das capacidades dos professores para refletirem e emitirem suas opiniões sobre as questões educacionais. Percebemos que as experiências advindas das vivências na escola, e de tudo o que os constitui pessoa e profissional, são desconsideradas.

Sentimos quão valioso é o acolhimento quando nos sentimos perdidos, ou percebemos que não sabemos algo; quando há insegurança; quando nos esquecemos de quem somos e daquilo tudo que carregamos em nossa bagagem, por não nos encontrarmos mais ao estarmos em um novo contexto e momento de nossa vida profissional - o início da carreira.

A partir de alguns fragmentos do retrato produzido por Roberta, entendemos as dificuldades e embates do início da carreira docente, e compreendidos por Huberman (2007) como o período de sobrevivência e descoberta, no qual as professoras procuram ajustar suas expectativas e ideais sobre a profissão às condições reais de trabalho que encontram, procurando lidar com uma série de limitações que atuam diretamente sobre seu trabalho, tentando permanecer na profissão e manter um certo equilíbrio diante dos sentimentos contraditórios que marcam a entrada na carreira, estão presentes não apenas ao iniciarem a carreira, mas surgem também ao passo que mudam o contexto de atuação, onde se faz necessária uma (re)adaptação de acordo com a realidade local. Acreditamos que o professor pode não mais ser um iniciante na rede de ensino, mas pode ser um iniciante na escola (PRÍNCEPE, 2017), a cada novo caminho na carreira.

Afirmamos a necessidade de que sejam organizados programas de inserção docente que respondam " [...] à concepção de que a formação de professores é um contínuo, que tem de ser oferecida de um modo adaptado às necessidades de cada momento da carreira 
profissional" (MARCELO GARCIA, 1999, p. 119). Na realidade, esses programas devem ser compreendidos como um "[...] elo imprescindível que deve unir a formação inicial ao desenvolvimento profissional ao longo da carreira docente". É necessário que levem em conta diferentes conhecimentos profissionais que orientam as práticas escolares adotadas pelas iniciantes e utilizem estratégias inovadoras, de forma a promover o desenvolvimento profissional docente.

Ainda que neste texto tenhamos socializado apenas considerações de Roberta, destacamos que a referida pesquisa deixou em evidência a implicação das professoras iniciantes em sua própria aprendizagem profissional da docência. Pela disposição para expor suas formas de atuação, mostram que, apesar de iniciantes e de todas as adversidades vividas nesse período da carreira, sentem-se capazes de tomar decisões e ter opiniões, na tentativa de permanecer e viver uma fase de estabilização na carreira (HUBERMAN, 2007).

A pesquisa também permitiu afirmar que há particularidades sobre aspectos que estão relacionados ao ser professor iniciante: o tempo delimitado por fases não se aplica da mesma forma a todos os professores; há docentes iniciantes que, mesmo vivendo o novo, devido ao apoio recebido na escola, passam por esse momento da carreira com maior facilidade e aprendizado; a mudança de escola e as equipes de trabalho das quais fazem parte são fatores que influenciam a ação no cotidiano escolar; os conhecimentos adquiridos ao longo de todo o percurso de formação vividos são importantes, mas no contexto da escola podem perder-se quando não há um trabalho coletivo; o professor na maioria das situações rende-se ao sistema instituído em cada escola como forma de preservar a si e ao seu trabalho (o que gera insatisfação), porém é uma briga que nem sempre compra, por ser novato, mesmo conhecendo seu direito; deseja uma gestão democrática, anseia por apoio dos coordenadores pedagógicos, e o entusiasmo e vontade de sentir-se pertencente são atributos que fazem com que continuem na profissão. Essa é a leitura que fazemos sobre o que é ser um professor iniciante, não nos prendendo apenas a esses fatores, pois não é possível apresentar um perfil pronto e acabado diante das diferentes realidades às quais o docente está exposto nesta fase de sua carreira.

\section{REFERÊNCIAS}

BAKHTIN, M. Estética da Criação Verbal. Introdução e tradução do russo Paulo Bezerra. São Paulo: Martins Fontes, 2003.

CAVACO, M. H. Ofício do professor: o tempo e as mudanças. In: NÓVOA, A. (Org.). Profissão Professor. Porto: Porto Editora, 1999, p. 155-191.

CHALUH, L. N. Formação e alteridade: pesquisa na e com a escola. Tese (doutorado) Universidade Estadual de Campinas. Faculdade de Educação. Campinas, SP, 2008.

CUNHA, M. I. da. Aprendizagem da docência em espaços institucionais: é possível fazer avançar o campo da formação de professores? Avaliação. Campinas; v. 19, n. 3, p. 789-

Comunicações | Piracicaba | v. $26 \mid$ n. $23 \mid$ p. 133-149| set.-dez. 2019 
802, nov. 2014. Disponível em: $<$ http://www.scielo.br/pdf/aval/v19n3/13.pdf $>$. Acesso em 17 set 2016.

CUNHA, M. I. da. Formação de professores: espaços e processos em tensão In: GATTI, B. A. et al. Por uma revolução no campo da formação de professores. São Paulo: Editora Unesp, 2015.

FONTANA, R. A. C. Trabalho e subjetividade. Nos rituais da iniciação, a constituição do ser professora. Cadernos Cedes, Campinas, ano XX, 2000; p.103-119.

FREIRE, P. Pedagogia da autonomia: saberes necessários à prática educativa. São Paulo: Paz e Terra, 2008.

GARCIA, C. M. Formação de professores: para uma mudança educativa. Porto: Porto Editora, 1999.

GARCIA, C. M. O professor iniciante, a prática pedagógica e o sentido da experiência. Formação Docente, Belo Horizonte, v. 02, n. 03, p. 11-49, ago./dez. 2010. Disponível em: $<$ http://formacaodocente.autenticaeditora.com.br $>$. Acesso em 02 Fev 2018.

GERALDI, J.W. A diferença identifica. A desigualdade deforma. Percursos bakhtinianos de construção ética e estética. In: FREITAS, M. T.; SOUZA, S. J.; KRAMER, S. (orgs). Ciências humanas e pesquisa: leituras de Mikhail Bakhtin. Cortez Editora, 2003; v. 107; p. 39-56.

GINZBURG, C. Sinais. Raízes de um paradigma indiciário. In: Mitos, emblemas, sinais. São Paulo: Companhia das Letras, 1989.

HUBERMAN, M. O Ciclo de vida profissional dos professores. In: NÓVOA, A. Org. Vidas de professores. 2. ed. Portugal: Porto Editora, 2007; p. 31-61.

LIMA, E. F. de (Org.). Sobrevivências no início da docência. Brasília: Líber Livro, 2006.

LIMA, M. E. C. C.; GERALDI, C. M. G.; GERALDI, J. W. O trabalho com narrativas na investigação em educação. Educação em Revista, Belo Horizonte, v. 31, n. 1, p. 17 44, jan./mar. 2015. Disponível em: <http://www.scielo.br/pdf/edur/v31n1/0102-4698edur-31-01-00017.pdf $>$. Acesso em 05 jun. 2016.

MARTINS, R. M.; SOUZA, A. P. G. de; OLIVEIRA, R. M. M. A. de. Licenciandas em pedagogia e professoras iniciantes: diálogo por meio de narrativas on line; 2017. Disponível em: <http://anais.anped.org.br/sites/default/files/arquivos/trabalho_38anped 2017 GT08 680.pdf $>$. Acesso em 02 Jun/ 2016. 
MIOTELLO, V. Empoderamento e linguagem. In: CHALUH, L. N. (Org.). Escola-universidade: olhares e encontros na formação de professores. São Carlos: Pedro \& João editores, 2012; p. 139-143.

MIZUKAMI, M. DA G. N. et al. Escola e aprendizagem da docência: processos de investigação e formação. São Carlos: EdUFSCar, 2002.

NÓVOA, A. Os professores e as histórias da sua vida. In: NÓVOA, A. Vidas de professores, 2. ed. Portugal: Porto Editora, 2007, p. 11-30.

NÓVOA, A. Conferência Desenvolvimento profissional de professores para a qualidade e para a equidade da aprendizagem ao longo da vida. Lisboa, 2007. Disponível em: <http://repositorio.ul.pt/handle/10451/687>. Acesso em: 6 fev. 2017.

PINTO, K. S. Desdobramentos das escritas de educadoras nos espaços de formação na escola. 187f. Dissertação (mestrado)- Instituto de Biociências de Rio Claro, Universidade Estadual Paulista, Rio Claro, 2016.

PRÍNCEPE, L. M. Condições de Trabalho e Desenvolvimento profissional de professores iniciantes em uma Rede Municipal de Educação. 232f. Tese (Doutorado em Educação: Psicologia da Educação), Pontifícia Universidade Católica de São Paulo, São Paulo, 2017. Disponível em: <https://tede2.pucsp.br/bitstream/handle/20409/2/Lisandra\%20Marisa $\% 20 \operatorname{Pr} \% \mathrm{C} 3 \%$ ADncepe.pdf $>$. Acesso em 28 maio 2018.

ROMANOWSKI, J.P.; MARTINS, P.L.O. Desafios da formação de professores iniciantes, Páginas de Educación, Montevideo, v.6, n.1, p. 1-17, 2013. Disponível em: < $\underline{\text { htp://www. }}$ scielo.edu.uy/pdf/pe/v6n1/v6n1a05.pdf>. Acesso em: 10 fev. 2018.

RUY, F. A. F. Retratos do início da carreira docente: nas experiências vividas, revelações da constituição do professor, 199s. Dissertação (mestrado) - Instituto de Biociências de Rio Claro, Universidade Estadual Paulista, Rio Claro, 2018.

TARDIF, M. Saberes docentes e formação profissional. Petrópolis: Editora Vozes, 2007.

VEENMAN, S. El Proceso de llegar a Ser Professor: um análisis de la formación inicial. In: VILLA, A. (Coord.) Perspectivas e problemas de la Funcion Docente. Madrid: Narcea, 1988.

ZEICHNER, K. Formando professores reflexivos para uma educação centrada no aprendiz: possibilidades e contradições. In: ESTEBAN, M. T.; ZACUR, E. (Org.). Professora pesquisadora: uma práxis em construção. Rio de Janeiro: DP\&A, 2002, p. 25-54. 


\section{Dados das aUtoras}

\section{Fabiana Alessandra Fonsaca Ruy}

Mestre em Educação pela Universidade Estadual Paulista. Rio Claro/SP - Brasil. Professora da Rede Municipal de Educação de Limeira. Limeira/SP-Brasil. fafonsaca@yahoo.com.br

\section{Laura Noemi Chaluh}

Professora. do Departamento de Educação e do Programa de Pós-Graduação em Educação do Instituto de Biociências da Universidade Estadual Paulista. Rio Claro/SP- Brasil. 1chaluh@rc.unesp.br

Submetido em: 3-1-2019

Aceito em: 26-6-2019 